\title{
OS CAMPOS DA HISTÓRIA E O PATRIMÔNIO CULTURAL: QUESTÕES PRELIMINARES.
}

Márcia Bortoli Uliana ${ }^{1}$

\begin{abstract}
Resumo: Este artigo compreende parte das discussões iniciais de minha tese em História, defendida em 2019, na UFGD. São questões preliminares acerca dos campos da História e o patrimônio cultural, em que faço considerações acerca da gestão compartilhada do patrimônio e o papel do município. Trato, em especial, do município de Dourados, que institucionalizou o patrimônio local através de decretos e leis municipais, incluindo o Conselho Municipal de Preservação do Patrimônio Histórico, Cultural e Ambiental entre as décadas de 1980 e 1990.
\end{abstract}

Palavras-chave: campos da História; patrimônio cultural; município.

\section{THE FIELDS OF HISTORY AND CULTURAL HERITAGE: PRELIMINARY ISSUES.}

\begin{abstract}
This article comprises part of the initial discussions of my thesis in history, defended in 2019, at UFGD. These are preliminary questions about the fields of history and cultural heritage, in which I make considerations about shared heritage management and the role of the municipality. In particular, I deal with the municipality of Dourados, which institutionalized the local heritage through decrees and municipal laws, including the Municipal Council for the Preservation of Historical, Cultural and Environmental Heritage between the 1980s and 1990s.
\end{abstract}

Keywords: Fields of History; cultural heritage; municipality.

\section{LOS CAMPOS DE HISTORIA Y PATRIMONIO CULTURAL: CUESTIONES PRELIMINARES.}

Resumen: Este artículo comprende parte de las discusiones iniciales de mi tesis en Historia, defendida en 2019, en UFGD. Estas son preguntas preliminares sobre los campos de la historia y el patrimonio cultural, en las que hago consideraciones sobre la gestión del patrimonio compartido y el papel del municipio. En particular, trato con el municipio de Dourados, que institucionalizó el patrimonio local mediante decretos y leyes municipales, incluido el Consejo Municipal para la Preservación del Patrimonio Histórico, Cultural y Ambiental entre los años ochenta y noventa.

Palabras clave: campos de Historia; patrimonio cultural; municipio.

\footnotetext{
${ }^{1}$ Doutora em História pela Universidade Federal da Grande Dourados (UFGD). Professora da Rede Básica de Ensino de Mato Grosso do Sul. E-mail: marcinhauliana@gmail.com.
} 
$\mathrm{O}$ fato de que patrimônio e temporalidades estejam indissoluvelmente ligados é uma evidência, já que o patrimônio é a reunião de semióforos criada por uma sociedade, em um dado momento (e por um momento). Eles traduzem então o tipo de relação que uma sociedade decide estabelecer com o tempo. O patrimônio torna visível, expressa uma certa ordem do tempo, na qual a dimensão do passado conta. Trata-se, porém, de um passado do qual o presente não pode ou não quer se desligar completamente. Quer se trate de celebrá-lo, imitá-lo, conjurá-lo, de extrair prestígio dele ou apenas de poder visitá-lo (HARTOG, 2014, p.197).

A categoria regime de historicidade utilizada pelo historiador francês François Hartog possibilita entender que "o tempo tornou-se tão habitual para o historiador, que ele o naturalizou ou instrumentalizou" (HARTOG, 2014, p.197). Numa relação contemporânea com o tempo vigora o "presentismo" como "um presente onipresente" (HARTOG, 2006, p.262), o que permite vislumbrar o lugar ocupado pelo patrimônio em relações sociais complexas. Para Hartog, patrimônio e memória são "palavras mestras", tratadas como "indícios e/ou sintomas" (HARTOG, 2014, p.245) de uma "crise" da ordem presente do tempo marcada pelo regime de historicidade calcado no presentismo. Quando o regime de historicidade é questionado ou tem decretado o seu final, o autor destaca que ocorreu uma crise nas relações da sociedade com o tempo, uma crise do e no tempo (HARTOG, 2003, p.10-11).

Hartog apropria-se da classificação proposta por Krzysztof Pomian, ao considerar o patrimônio como uma "reunião de semióforos", “objetos visíveis investidos de significações". Observa-se que o patrimônio é uma construção, pautada na atribuição de valores, mediada por interesses e disputas de poder presentes em determinado tempo e sociedade, estando relacionado às temporalidades. O passado, ao ser alvo de questões do presente, é selecionado a fim de "celebrar", "imitar", "conjurar", "extrair" e/ou "visitar" de acordo com as "necessidades de um tempo presente", que busca prender-se a ele ou desligar-se dele.

Analisar o patrimônio cultural não é tarefa simples em meio a um complexo de situações que o envolve, incluindo recortes, escolhas e limites. Muitos sujeitos envolvidos com a questão circulavam e integravam diferentes grupos e espaços, por vezes, ao mesmo tempo. Lori Alice Gressler, por exemplo, entre as décadas de 1980 e 1990, foi vereadora, professora universitária e membro-fundadora da Academia Douradense de Letras (ADL) (VASCONCELOS, 2014, p.192-197), ocupando papel importante na elaboração de políticas voltadas para o patrimônio cultural local. 
Ao pensar o patrimônio cultural na cidade de Dourados observam-se diversos embates em diferentes instâncias, como no interior do poder público municipal, envolvendo o Legislativo e o Executivo. Além da preocupação com o possível diálogo entre sujeitos ou grupos que atuaram em Dourados e que fizeram usos do passado, o patrimônio, por vezes, foi convocado. Junto dele, a história, a memória, a identidade foram utilizados na leitura e na produção de narrativas diferenciadas nas "reconstruções" no presente, acerca do passado douradense.

De acordo com Margaret Macmillan, os historiadores não são donos do passado, ele pertence a todos nós, porém, “como os historiadores gastam seu tempo estudando a história, estão numa posição melhor para fazer juízos equilibrados do que os amadores. Os historiadores, afinal, são treinados para fazer perguntas, estabelecer conexões, coletar e examinar provas" (MACMILLAN, 2010, p.61). Nesse sentido, ainda, para a autora, "a história não deve ser escrita para fazer com que a atual geração se sinta bem, mas para nos lembrar de como as relações humanas são complexas" (Idem, p.157).

Muito mais que tentar analisar a complexidade do patrimônio cultural, é preciso compreender suas definições, contradições e usos em diversas faces, entre elas, como instrumento político utilizado por representantes/agentes do poder público municipal. Além disso, ler o patrimônio cultural através das representações e da esfera pública nos remete ao patrimônio cultural como objeto da história, repensando o trabalho do historiador, não apenas como sujeito que escreve, mas como sujeito integrante e atuante dentro e fora da academia, o que exige "um olhar" minimamente interdisciplinar em consonância com diversas temporalidades.

Assim, não se pode negar a reescrita sobre o passado de acordo com as mudanças no tempo. A História que lida com tais mudanças, ao mesmo tempo se transforma. Para Sandra Jatahy Pesavento, ao analisar a reescrita da História através da História Cultural:

[...] mudou o mundo, mudou a história, mudaram os historiadores. Mudamos, sim, mas desde quando? Trata-se, aparentemente, de mais uma reescrita da História, pois a cada geração se revisam interpretações. Afinal, a História trabalha com a mudança no tempo, e pensar que isso não se dê no plano da escrita sobre o passado implicaria em negar pressupostos (2012, p.16).

Para Roger Chartier “[...] a história cultural se tornou um dos campos mais vigorosos e debatidos do âmbito histórico" (2010, p.33). Traçar os limites da História Cultural, assim 
como suas fronteiras, não é iniciativa fácil. No entanto, pode-se "mudar de perspectiva" e considerar que "toda história é cultural" e "[...] sempre resultado das significações que os indivíduos atribuem às coisas, às palavras, às ações" (Idem, ibidem).

Para outro historiador, Peter Burke, entre as décadas de 1960 e 1990, a História Cultural esteve em proximidade com a Antropologia, sendo considerada na França como "Antropologia histórica" (2005, p.44). Todavia, isso não foi exclusivo da História Cultural, pois a aproximação com a Antropologia pode ser explicada pelas múltiplas acepções do termo "cultura" através do uso do termo no plural (CHARTIER, 2010, p.34).

A denominada Nova História Cultural, como defendida por Lynn Hunt (1992), trouxe novas perspectivas para a História lidar com a cultura. Segundo Pesavento, "trata-se, antes de tudo, de pensar a cultura como um conjunto de significados partilhados e construídos pelos homens para explicar o mundo" (2012, p.15). E mais,

[...] a cultura é ainda uma forma de expressão e tradução da realidade que se faz de forma simbólica, ou seja, admite-se que os sentidos conferidos às palavras, às coisas, às ações e aos atores sociais se apresentem de forma cifrada, portanto, já um significado e uma apreciação valorativa (Idem, ibidem).

A complexidade da cultura e de seu entendimento na produção acadêmica e, em especial, na historiografia, tem sido, de acordo com as mudanças observadas no "fazer histórico" nas últimas décadas, vinculadas as "rupturas epistemológicas" da "crise de paradigmas explicativos da realidade", que estimularam "outras questões", "outros problemas", "outros campos e temas". Para Pesavento, a partir dos anos de 1990 ocorreu no Brasil "uma verdadeira virada nos domínios de Clio", citando a História Cultural como sua "faceta mais recente e difundida". Segundo ela, "foi, sem dúvida, um contexto histórico preciso e datado que produziu essa mudança que, em última análise, pode ser vista como um ajustamento da realidade do mundo às formulações explicativas do homem para dar conta do próprio mundo" (Idem, ibidem). Como consequência, a História Cultural está presente numa "reinvenção do passado que se constrói na nossa contemporaneidade", pois "o conjunto das ciências humanas encontra seus pressupostos em discussão". Muito embora a História Cultural receba críticas diversas, sua heterogeneidade é nítida entre os historiadores que tratam do "cultural", assim como são as acepções dadas à cultura. 
Numa "perspectiva panorâmica", Chuva evidenciou "a ampliação da noção de patrimônio no Brasil" na década de 1980, sobretudo, ao analisar as publicações do IPHAN por diversos autores. Esse "deslocamento" ocorreu num

[...] contexto de profundas transformações epistemológicas nas ciências sociais como um todo [incluindo aí a história], e as perspectivas que prevaleciam nesses movimentos reagiam também às novas visões no campo do patrimônio. De modo geral, percebeu-se que a realidade só poderia ser apreendida por meio de representações, sempre mediadas por esquemas conceituais, simbólicos ou interpretativos, como lentes que alternariam as visões de mundo de acordo com os sujeitos que delas dispusessem (CHUVA, 2015, p.12).

Ainda segundo a autora, o "deslocamento" estaria no fato de que a valorização dos bens culturais não estava mais vinculada ao valor em si, mas a partir dos sentidos atribuídos aos bens culturais. Ao especialista caberia passar a "conhecer as diversas falas e interpretações acerca do bem e inventariar os diferentes saberes a seu respeito, a começar pelos próprios sujeitos produtores e/ou diretamente envolvidos com a vida e a dinâmica do bem em questão" (Idem, p.13-14). Tais transformações ocorreram não apenas nas ciências sociais e na História, mas no "perfil dos quadros do IPHAN" no contexto de redemocratização brasileira, entre os anos de 1970 e 1980. Chuva ainda cita as "batalhas" e as "dissonâncias" no bojo desse "deslocamento", considerando-o como um novo paradigma. Para a autora, as tensões e embates no interior do campo do patrimônio "revelavam novas perspectivas em debate e, como representações, alternavam, na prática, as próprias configurações no campo" (Idem, p.15).

Outros autores, como Nogueira (2014) e Possamai (2018), defendem a perspectiva de análise do patrimônio cultural como um campo, por meio do conceito de Pierre Bourdieu, num desafio à interdisciplinaridade com ênfase na compreensão do "lugar da História no campo do patrimônio". Para Possamai, o patrimônio "passou, paulatinamente, a figurar entre outros tantos objetos com legitimidade nas investigações dos programas de pós-graduação em história", ressaltando o papel da História Cultural como aquela que "proporcionou o substrato teórico e metodológico para a acolhida de objetos até então inusitados para a historiografia, como o patrimônio, monumentos, museus ou arquivos" (POSSAMAI, 2018, p.33).

Na França, onde primeiro se adotou a noção de patrimônio cultural no final dos anos de 1950, nas décadas que se seguiram observou-se a propagação da noção de patrimônio cultural. Cabe lembrar que a hipertrofia do patrimônio está associada às décadas de 1960 e 
1970, com a atuação da Organização das Nações Unidas para a Educação, a Ciência e a Cultura (UNESCO), Conselho Internacional de Museus (ICOM), Conselho Internacional de Monumentos e Sítios (ICOMOS), Centro Internacional de Estudos para a Conservação e Restauro de Bens Culturais (ICCROM), centrados na ideia de patrimônio cultural da humanidade. Como observado por Hartog, no cenário francês, 1980 foi considerado o "ano do patrimônio". Ali, tais aspectos estão inter-relacionados ao sentido memorial do patrimônio e a gênese dos "lugares de memória", porém, segundo Santiago Júnior, esta inter-relação pouco foi explorada a partir da semântica patrimonial (2015, p.261).

Nas análises de Koselleck ocupa lugar a história dos conceitos, entendidos como polissêmicos, contendo em si uma multiplicidade de significados (2006, p.109) que pode ser analisada através da historicidade das palavras (FEBVRE, 1998, p.53). Neste sentido, pode-se agregar à pesquisa o patrimônio cultural como conceito possível de ser compreendido historicamente em suas mudanças e permanências, "de modo que, ao longo do tempo, também o significado do conceito tenha sido submetido a uma alteração histórica”, como apontado por Koselleck (2006, p. 105).

De acordo com Santiago Júnior, o cenário de reivindicações pelo "direito a memória" de vários grupos, chamados de minorias, desde os anos 1960, parece ter sido, em parte, responsável pela notoriedade da memória. Segundo o autor, "a abertura para a cultura do patrimônio demonstra que o lugar da memória, em vez de um ritual de uma sociedade com memória fraturada, é um exercício múltiplo de formação dos passados das diversas comunidades políticas" (SANTIAGO JÚNIOR, 2015, p.262). O patrimônio cultural foi inflacionado no final do século XX e tornou-se "componente cultural do pertencimento de uma comunidade política" (Idem, p. 256). Para tanto, o aspecto memorial acompanhou a expansão do patrimônio e os sentidos atribuídos a ele ultrapassou o uso memorial. Outros valores, além da "vontade de memória", foram agregados ao conceito ampliado de patrimônio e as identidades culturais.

Dentre as discussões do "direito a memória", as definições e os variados usos do patrimônio e, por sua vez, da cultura, cabe destacar a experiência institucional de Marilena Chauí, entre 1989 e 1992, junto a Secretaria Municipal de Cultura de São Paulo (SMC-SP). Ao considerar os múltiplos significados da cultura, Chauí "presta contas" de sua atuação à frente da Secretaria e da proposta da "cidadania cultural", considerando práticas voltadas à cultura na gestão municipal. 
O projeto que norteou a gestão de Chauí na SMC-SP considerava “[...] a cultura como direito dos cidadãos e como trabalho de criação" (CHAUÍ, 2006, p.67) e propunha “[...] uma tomada de posição quanto ao modo de inserção da cultura na sociedade de classes, na república e na democracia" (Idem, p.69). Na política de cidadania cultural, a cultura foi considerada um instrumento para participar, criar, refletir e como direito do cidadão, os antagonismos e os conflitos de classe não foram silenciados, pelo contrário, foram evidenciados para produzir mudanças. Para a filósofa, “[...] a política cultural de um órgão público precisa ir além do campo clássico, definido no século XVIII, da cultura identificada com a esfera das belas-artes, e caminhar para a efetuação da política cultural e da cultura política" (Idem, p.65). Dentre as "três concepções de política cultural que, em diferentes conjunturas, se consolidaram nos órgãos públicos de cultura: a da cultura oficial produzida pelo Estado, a populista e a neoliberal” (Idem, p.67), Chauí propôs uma quarta,

[...] aquela que restringe o Estado à condição de assegurador público de direitos, prestador sócio-político de serviços e estimulador-patrocinador das iniciativas da própria sociedade, enfatizando a natureza de classe da nossa sociedade e a obrigação de uma política, se quiser ser moderna e democrática, de garantidor de direitos, quebrar privilégios, fazer ser público o que é público, abrir-se para os conflitos e para as inovações (Idem, p.62).

A autora apontou o aprendizado no "exercício" de "romper para criar", com políticas administrativas que poderiam fortalecer as atividades culturais autônomas e livres. Como práticas para quebrar barreiras, citou a implementação de conselhos participativos para permitir a efetivação da política de cidadania cultural. No entanto,

[...] seriam os conselhos municipais a emergência de um novo regime de ação pública, decorrente tanto do fortalecimento da esfera municipal de governo quanto da maior presença dos atores sociais na cena pública? E, a experiência dos conselhos municipais pode aprofundar nossa democracia e possibilitar a instituição de modelos mais democráticos de gestão municipal? (SANTOS JÚNIOR; AZEVEDO; RIBEIRO, 2004, p.08).

É desta pretensão em entender o papel do município diante da gestão compartilhada do patrimônio parte da abrangência deste texto. Em Dourados, o contexto do final da década de 1980 foi marcado por contradições e usos políticos do patrimônio cultural em consonância com as discussões, inicialmente, no Legislativo Municipal, que configuraram a Lei Orgânica Municipal (LOM) em estreita relação com a amplitude e diversidade trazidas pela CF88 e, por 
sua vez, no projeto $n^{\circ}$ 021/90, que se tornou Lei Complementar $n^{\circ}$ 02/90, regulamentando o Conselho Municipal de Preservação do Patrimônio Histórico, Cultural e Ambiental de Dourados.

Em meio à criação deste Conselho Municipal, outras leis instituíram o que representaria o patrimônio local. Ao longo de pouco mais de três décadas e cerca de trinta leis, a prática de patrimonializar bens culturais foi protagonizada pelo poder público municipal, mesmo após a criação do Conselho Municipal. Ao mesmo tempo, quando se elaboraram projetos e leis municipais, o poder público pouco fez para garantir sua preservação. As leis municipais aprovadas à revelia, em diferentes gestões políticoadministrativas, expressaram práticas e representações de usos do patrimônio, da cultura, da política, da memória e da identidade.

\section{A gestão compartilhada do patrimônio: o papel do município}

Dourados tem sido analisada por meio de inúmeras perspectivas no campo da História (SANTOS, 2016), porém, o patrimônio cultural ainda é pouco vislumbrado em produções acadêmicas. É a segunda maior cidade de Mato Grosso do Sul, considerada uma cidade média, em saúde, educação, serviços, agronegócio. Não é uma referência em patrimônio cultural se comparado aos municípios citados pelo IPHAN/MS e pela Fundação de Cultura do Estado, como Corumbá, Bonito, Alcinópolis, Campo Grande, Aquidauana, entre outros. No entanto, Dourados foi o primeiro município de Mato Grosso do Sul a instituir uma política voltada para o patrimônio cultural através da elaboração e aprovação do Conselho Municipal de Preservação do Patrimônio Histórico, Cultural e Ambiental de Dourados, entre 1989 e $1990^{2}$.

\footnotetext{
${ }^{2}$ Ao observar o Mato Grosso do Sul, no tocante às políticas municipais para a cultura, há no "perfil dos municípios brasileiros", dados de 2014 disponibilizados pelo IBGE, um campo específico voltado à "legislação municipal" e em especial a "legislação proteção ao patrimônio cultural". Neste item é observada a existência de legislação proteção contendo o ano da lei e a "a natureza dos bens tombados na legislação" em categorias separadas ("patrimônio material", "histórico", "artístico", "arqueológico", "paisagístico", "outros" e "patrimônio imaterial"). Há também espaço para observar se "estão sendo conduzidos projetos municipais associados aos bens tombados (patrimônio material e imaterial)" e descrevem o "tipo de projeto" ("social", "econômico", "ambiental", "institucional", "cultural", "educação patrimonial" e "outros"). Ali o patrimônio é material, histórico e imaterial e, por sua vez, consta que Dourados não possui um plano municipal de cultura. Cf. Perfil dos municípios brasileiros. IBGE. Pesquisa de Informações Básicas Municipais, Suplemento de Cultura -2014. Disponível em 〈https://ww2.ibge.gov.br/munic cultura 2014/sel tema.php?munic=5003702\&uf=50\&nome> acesso em 24 dez. 2017.
} 
A descentralização do Estado brasileiro, organizado como Federação, entre os anos de 1970 e 1980, após o final do regime militar, permitiu certa autonomia aos municípios. De acordo com Conciani e Santos:

a Federação é tida como solução normal para a União, em uma só potência mais forte, de estados que dificilmente se sustentariam sozinhos. Tal realidade é vista mundo afora. Por outro lado, é também instrumento artificial que visa facilitar o governo que tenha território continental ou para satisfação de aspirações locais. Este último seria o caso brasileiro. Desta forma, a criação brasileira foi nada mais que uma maneira constitucional de descentralizar o poder político (2009, p.280).

A descentralização do poder político permite que interesses locais possam ser aspirados, disputados e atendidos. Diante da autonomia concedida aos municípios, o patrimônio cultural se insere nos atos do Legislativo e do Executivo, porém, não se restringe ao poder público municipal. Ainda, segundo Conciani e Santos

[...] o texto constitucional veio reforçar a ideia de Estado Federal, mantendo a autonomia dos entes federados e visando ao desenvolvimento harmonioso entre eles. Dito de outro modo, com a Constituição de 1988, Estados e Municípios tiveram suas competências ampliadas, caracterizadas pela capacidade de legislar, de auto-organização, de autogoverno e de autoadministração [...] notadamente a liberdade concedida aos entes federados deve observar os princípios constantes na Constituição Federal (supremacia constitucional) (Idem, p.278).

A organização político-administrativa do Estado brasileiro baseia-se em competências e atribuições específicas interligadas entre Municípios, Estados-membros, Distrito Federal e a União. A Constituição Federal de 1988 garante tais competências e atribuições e deve ser obedecida por todos os entes federados. Ao mesmo tempo, o federalismo brasileiro tem sua centralização na União, pois distribui competências que a privilegia (Idem, p.276). Neste sentido, "trata-se de um sistema político em que Municípios, Estados e Distrito Federal, sendo independentes um do outro, formam um todo que valida um Governo Central e Federal” (Idem, p.277).

Segundo Lino, a CF88 garantiu o "federalismo cooperativo" aos entes federados e a possibilidade de convênios de cooperação no exercício da competência de cada um. Falta, por vezes, vontade política de fazê-lo. Para a autora, na CF88 “[...] a preservação do patrimônio cultural brasileiro consagrou-se como questão que interessa a toda a Federação, incumbindo 
seu exercício - verdadeiro poder - dever - indistintamente à União, aos Estados membros, ao Distrito Federal e aos Municípios” (LINO, 2010, p.49). Em suma, conforme Lino, a “[...] União caberia a decisão comum, tomada em escala federal e aos Estados e Municípios competiria adaptar essa decisão as peculiaridades e necessidades regionais e locais, além de executá-la autonomamente" (Idem, p.56). Neste sentido, “o tombamento pode ser feito pela União, por intermédio do IPHAN, pelos governos estaduais, por meio de suas instituições responsáveis pela área, ou pelas administrações municipais, segundo leis específicas ou a legislação federal" (IPHAN, 2018).

Segundo Meneses (2012), a transformação principal do patrimônio feita pela CF88 foi o "deslocamento da matriz", isto é, as comunidades locais passaram a ter possibilidades de eleger seus patrimônios culturais e, por sua vez, o Estado brasileiro deixou de ser o protagonista nesse processo. Em Dourados, o poder público municipal foi, em grande parte, o protagonista nas propostas de patrimonialização, considerando uma leitura limitada da CF88 e da LOM, mas agindo em acordo com práticas implementadas ao longo de décadas de centralização na seleção, gestão e preservação do patrimônio cultural brasileiro. Ao mesmo tempo, se autoafirmaram identidades de grupos sociais através das patrimonializações.

De acordo com Chuva, em artigo publicado numa das edições especiais de comemoração dos 80 anos do IPHAN, em 2017, a CF88 não apenas ampliou a noção de patrimônio cultural, mas consolidou “[...] uma perspectiva ampla e plural da identidade brasileira e trazendo para a cena jurídico-política a noção de bens culturais de natureza imaterial” (CHUVA, 2017, p.88). Além disso, considerou “"[...] a importância da contribuição dos 'diversos grupos formadores da sociedade brasileira' e a necessidade de proteção e salvaguarda do patrimônio cultural [...] pertencente a esses diferentes grupos" (Idem, p.89). No entanto:

[...] refletindo sobre a eficácia da noção de "grupo" após o transcurso de algumas décadas e das novas configurações do campo, alguns dos efeitos da sua apreensão como algo permanente podem ser verificados na prática de seleção de bens culturais como patrimônio: se por um lado essas práticas ampliaram significativamente o universo de bens tombados, com elementos de representação do imigrante, do afrodescendente ou do indígena, por outro, ficou evidente o objetivo de somar grupos distintos, como se fosse possível alcançar uma totalidade, isto é, um somatório de diferenças prontas. Esse modo de perceber a realidade levou à colocação de uma falsa pergunta, repetida em diferentes situações: como contemplar todos os grupos que constituem a nação? Isso só seria possível se tais grupos fossem tipificados e estanques. Os grupos formadores da sociedade brasileira são configurações 
históricas, portanto, mutáveis, sempre em processo de formação e transformação (Idem, p.89-90).

Sujeitos ou grupos atuam na construção e autoafirmação de identidades sociais através de disputas e reivindicações. Para tanto, observa-se que o patrimônio cultural não está vinculado a uma identidade social monolítica, mas a de diferentes grupos. Na crescente patrimonialização muitas foram as implicações para se atender a diversidade cultural explicitada com a CF88. O patrimônio cultural imaterial brasileiro ainda necessitaria de outros mecanismos para ser assegurado, como a Carta de Fortaleza, em 1997, o Decreto ${ }^{\circ}$ 3551 de 2000, as Cartas Patrimoniais e as Convenções da UNESCO.

Uma das questões é que grupos não são homogêneos e a representatividade de suas culturas não se reduz aos bens culturais que são patrimonializados. Pelo contrário, o que deveria ser patrimonializado, num primeiro momento, precisa ter significância, valor atribuído. Outra é que se patrimonializaria o ameaçado, correndo risco de desaparecimento ou dificuldades de continuidade de práticas ou "saber-fazer". Em vários momentos, as patrimonializações que ocorreram, mediante projetos e leis municipais, não se orientaram pela ameaça de perda, ao contrário, se deram através das disputas de poder e em virtude da autoafirmação identitária de sujeitos ou grupos, ditos como pertencentes à história e à memória de Dourados.

Logo, agentes políticos assumiram a liderança pela propositura de projetos de lei e saíram em "defesa" através da imprensa local, pouco recorrendo à participação de integrantes de grupos interessados. Nessa direção, Meneses ressaltou a necessidade de "repovoar o patrimônio urbano", em inserir os interlocutores, protagonistas nos processos de patrimonialização (MENESES, 2017, p. 40-41), pois

[...] como pode algo valer para o mundo todo, se não vale para aqueles que dele poderiam ter a fruição mais contínua, mais completa, mais profunda? Como pode o patrimônio mundial não ter, antes, valor municipal? [...] aliás, é necessário repensar a escala de alcance dos bens culturais (municipal, estadual, federal), quase sempre definidos a partir de critérios jurídicoadministrativos ou quantitativos ou segundo apenas a extensão espacial da ocorrência $[. .$.$] é preciso introduzir outros critérios para avaliar os círculos$ concêntricos de pertinência e interesse do bem, que possam antes de mais nada definir seu potencial de interlocução. A grande referência deveria ser esse potencial de interlocução, começando sempre com os interlocutores locais. (2012, p.25-39). 
No entanto, ainda a materialidade e a estética, em sua maioria, representam o patrimônio cultural institucionalizado. De acordo com Campos,

[...] a imaterialidade de todo patrimônio [...] está nos valores que lhe são atribuídos e nos saberes necessários para a sua execução ou concretização, ou, ainda, nos processos necessários para sua realização, muito mais do que no produto final a que se chega. Portanto, pode-se notar que as práticas de preservação do patrimônio cultural ainda estão marcadas pela valorização estética, isto é, baseadas ainda na compreensão de que os valores de um bem são intrínsecos a ele e não atribuídos pela comunidade; nota-se, ainda, como o patrimônio cultural é embebido em discursos políticos e sua seleção e preservação surgem de conflitos entre identidades, sejam locais ou globais (2017, p.05).

Não cabe aqui destrinchar aspectos que competem aos entes federados, mas de observar a inserção dos municípios na institucionalização do patrimônio cultural. Na relação entre Municípios, Estados, Distrito Federal e a União devem-se destacar os Compromissos de Brasília, em 1970, e de Salvador, em 1971, que sinalizaram ações específicas para a área do patrimônio cultural. No entanto, reforçaram a perspectiva do Estado brasileiro em atuar na construção e gestão do patrimônio cultural brasileiro através do IPHAN. Na gestão de Renato Soeiro (1967-1979) foi organizado o "encontro de governadores e prefeitos", sendo recomendadas ações articuladas entre os poderes federal, estadual e municipal. Cabe frisar que, em edição especial, em 2017, aos 80 anos do IPHAN, de acordo com Azevedo, era necessário "convocar novamente os governadores e prefeitos, recolocar o patrimônio, sem divisões, na agenda nacional e descentralizar a ação como se fez na década de 1970" (2016, p.254).

Entre os "compromissos", no início da década de 1970, e as comemorações dos 80 anos do IPHAN, em 2017, fez-se um paralelo. São momentos distintos, no entanto, implicam em observar "quem" e "como" se atua, ainda de maneira institucional, sobre o patrimônio cultural brasileiro. Ainda discute-se, dentre o campo do patrimônio cultural, não apenas a sua concepção, noção e/ou conceito, mas as possibilidades de gestão e de preservação, sobretudo, no tocante a participação mais ampla de pessoas e o papel do poder público ao administrá-lo. Muito embora a CF88 tenha aberto caminhos para a participação popular, o Estado ainda é visto como condutor de ações e mediador dos interesses em jogo (LINO, 2010, p. 43). Todavia, é possível que se façam parcerias entre diferentes órgãos e instituições privadas, visto desde os anos 1990. 
Após a promulgação da Constituição Federal de 1988, coube aos municípios, assim como aos estados ${ }^{3}$, elaborar suas constituições. Denominada de Lei Orgânica do Município (LOM), a de Dourados foi aprovada em 05 de abril de 1990. A elaboração do Conselho Municipal de Preservação do Patrimônio Histórico, Cultural e Ambiental de Dourados, ocorreu em conjunto com os debates da LOM e era para ser incluído nela. Como resultado, ficou de fora devido à aprovação do Conselho Municipal de Cultura. A proposta do Conselho, específica para o patrimônio, tornou-se Lei Complementar, logo em seguida, em 09 de novembro de 1990.

O Conselho Municipal de Preservação do Patrimônio Histórico, Cultural e Ambiental de Dourados, instituído como lei complementar foi, em parte, um avanço do poder público municipal douradense diante das patrimonializações que estavam sendo feitas, em sua maioria, no Legislativo. De acordo com Conciani e Santos "pelo fato de os municípios terem determinada autonomia configurada através de auto-governo e auto-administração”,

[...] a primeira é visualizada por Poderes próprios, como o Executivo, representados pelo Prefeito e Legislativo representado pelos Vereadores; e a segunda pelo exercício de competências, como por exemplo, administrativas e tributárias. Quanto à competência, podemos destacar o chamado "interesse local" como forma de delimitação da mesma, apesar de muito pouco precisa sua definição pela Constituição. Além desta competência legislativa exclusiva, o município pode legislar de forma suplementar (art.30, II CF-88), e possui competência administrativa própria (art.30 CF-88), além da competência administrativa comum (art. 23 CF-88). (CONCIANI; SANTOS, 2009, p. 275).

A atuação do poder público municipal no tocante ao patrimônio cultural local pode ser analisada não apenas pela propositura de projetos de lei, decretos e leis municipais, mas pelas discussões envolvendo votos contrários, pela procrastinação em debates e aprovações por unanimidade que revelam as características de aprovação aleatória ao longo das últimas décadas.

Nas leituras de projetos de lei que serviram de base para a criação de leis municipais que tombaram/registraram bens culturais em Dourados, encontrou-se no Projeto de Lei (PL) n 40/1991 o "Regulamento do Conselho de proteção ao patrimônio histórico do município de Dourados". O regulamento fez referência à criação do Conselho como autarquia sob a lei n $^{\circ}$ 12 de 10 de setembro de 1982, porém, mencionou uma "suposta aprovação", sem data, em

\footnotetext{
${ }^{3}$ A Constituição do Estado de Mato Grosso do Sul foi promulgada em 05 de outubro de 1989. 
1985. Após análise mais detalhada, não se encontrou a lei no livro de registros do acervo da Câmara de Vereadores, o que deixou lacunas quanto ao funcionamento daquele regulamento, embora sabe-se que ocorreram discussões em torno do "patrimônio histórico" em Dourados, antes da criação do projeto de lei encampado pela vereadora Lori Alice Gressler, em 1989. Segundo Machado, "no Brasil, a redemocratização e a mobilização que antecedeu a elaboração da Constituição Federal de 1988 foram estimuladoras de revisões importantes nos critérios de preservação" (MACHADO, 2009, p.141). Em Dourados, a criação da FUNCED e as comemorações do cinquentenário da cidade, na década de 1980, podem ter integrado um ambiente de mobilização pela preservação do patrimônio local.

Ao longo da feitura de minha tese, foram encontradas leis municipais que trataram da instituição do patrimônio local, desde 1984. Sabe-se que até a aprovação da Lei Complementar $n^{\circ}$ 02/90 alguns tombamentos foram realizados. Nestes, figuraram, árvores, como duas figueiras e a Colônia Agrícola Nacional de Dourados (CAND). A patrimonialização do Cruzeiro e da Casa de Madeira em proximidade aos cinquentenários de Dourados, em 1985, e da CAND, em 1993, se inseriu num contexto em que a proposta de criação de um Conselho Municipal específico ao patrimônio local fosse desencadeada e, por conseguinte, aprovada como lei complementar.

\section{Entre decretos e leis municipais: a institucionalização inicial do patrimônio local pelo poder público municipal}

O Projeto de Lei $n^{\circ} 14 / 84$, proposto pelo vereador Vitório José Pederiva do Partido Democrático Social (PDS) tornou-se a Lei Municipal n 1293/1984, durante a gestão políticoadministrativa de Luiz Antônio Álvares Gonçalves (1983-1988) e tombou, para o patrimônio histórico do município, duas figueiras. O vereador destacou uma delas por situar-se próxima a "residência do saudoso e arrojado Marcelino Pires". Localizada em frente à empresa Comércio de Máquinas e Implementos Douradense (COMID), num cruzamento que se inicia na MS 162, ressaltou-se que a figueira era "sem dúvida uma das glórias de nossa terra", que "sob suas ramadas diferentes camadas sociais num passado não muito remoto" aguardavam "os coletivos que seguem ainda hoje rumo à fronteira" 5 . A outra figueira, localizada na Rua

\footnotetext{
${ }^{4}$ Marcelino José Pires Martins ou apenas Marcelino Pires é referenciado por ter sido um dos fundadores e pioneiros de Dourados. Entretanto, seu papel tem sido questionado por outros pioneiros como aqueles que compõem o Centro Cívico, Histórico e Cultural 20 de Dezembro.

5 “Justificativa". Projeto de lei nº 14/1984, fls 01.
} 
Albino Torraca, entre as avenidas Weimar Gonçalves Torres e Marcelino Pires, que não existe mais, teria sido plantada por Maria da Glória Muzzi Ferreira ${ }^{6}$, "uma das mais refinadas damas de nossa sociedade e que teve em toda a sua magnífica existência uma atuação cívica que merece nosso respeito, mercê de seu alto grau de brasilidade" ${ }^{7}$. De acordo com o vereador Pederiva, as duas figueiras eram "um patrimônio histórico e cultural de Dourados, que já possui sua comissão de esportes e cultura a qual deve abarcar esse patrimônio" ${ }^{8}$. Os pareceres foram favoráveis em todas as comissões, a de Justiça, Legislação e Redação, a de Obras, Serviços Públicos e Planejamento e a de Educação e Cultura.

Duas figueiras, escolhidas por representarem Marcelino Pires, que hoje nomeia a principal avenida da cidade, e Maria da Glória, que denomina instituição estadual de ensino básico, pouco tratam das questões ambientais, da relevância do espécime, do conjunto em que se insere. Apenas o exemplar e a "excepcionalidade dos sujeitos" foram associados à figueira. Ainda, une-se a "glória e a brasilidade", um tom heróico a "pessoas destacáveis". Vale lembrar que, em 1984, houve iniciativas de diferentes sujeitos e grupos para a patrimonialização do Clube Social, no entanto, o tombamento não foi realizado. ${ }^{9}$

Em 1985, ano do cinquentenário da cidade de Dourados, o prefeito Luiz Antônio Álvares Gonçalves tombou, via Decreto Municipal no 75, de 20 de setembro de 1985, um conjunto de figueiras. Doze figueiras na Rua João Cândido Câmara, entre as ruas João Vicente Ferreira e Oliveira Marques, dezessete figueiras (até 2015, consta em Ação Civil Pública, apenas 12) na Avenida Presidente Vargas, entre a Avenida Marcelino Pires e a Rua Onofre Pereira de Matos e outras nove na Rua João de Rosa Góes, entre as ruas Joaquim Teixeira Alves e Cuiabá ${ }^{10}$. O decreto municipal fez referências às figueiras plantadas num período de colonização promovida pela CAND, mesmo sendo o ipê amarelo escolhido para representar Dourados como símbolo no seu cinquentenário e sendo plantado em vários espaços da cidade, incluindo a Praça do Cinquentenário.

Posteriormente, outros tombamentos foram realizados, os quais envolviam árvores localizadas em diferentes pontos da cidade, como espécimes de figueira ${ }^{11}$ em 2003, jequitibá ${ }^{12}$

\footnotetext{
6 Maria da Glória Muzzi Ferreira foi vereadora, em Dourados, no final da década de 1950. Cf. 〈http://www.luiscarlosluciano.com.br/fotosnoticias/dourados.pdf> p.36.

7 "Justificativa". Projeto de lei no $14 / 1984$, fls 01.

8 "Justificativa". Projeto de lei n ${ }^{\circ} 14 / 1984$, fls 02.

${ }^{9}$ Cito a pesquisa, em andamento, no PPGH-UFGD, de Maiara Laís Pinto, intitulada "O patrimônio históricocultural de Dourados em tempos de transformação social e urbana: uma análise através do movimento de preservação do Clube Social de Dourados (1984-1986)", orientada pelo prof ${ }^{\circ}$ Dr. Paulo Roberto Cimó Queiroz.

${ }^{10}$ Decreto municipal $\mathrm{n}^{\circ} 75$ de 20 de setembro de 1985.

${ }^{11}$ Projeto de lei no $035 / 2003$. Lei municipal no2571 de 16 de junho de 2003.
} 
em 2005, seringueira ${ }^{13}$ e figueira ${ }^{14}$ em 2010 , em diferentes gestões político-administrativas. Árvores de determinadas espécimes foram escolhidas em detrimento de reservas, áreas de proteção ambientais ou parques municipais. Dentre as características excepcionais, belezas estéticas e cênicas dos exemplares patrimonializados esboçaram-se uma valoração paisagística do patrimônio ambiental em Dourados. As árvores, em sua maioria, as figueiras, foram associadas à memória de sujeitos considerados "pessoas ilustres" que deveriam servir de exemplo a população.

Durante as comemorações do cinquentenário da cidade e nos anos que se seguiram, a CAND foi ressaltada, geralmente, associada à figura de Getúlio Vargas, idealizador das colônias agrícolas federais. Investiu-se de maneira incisiva em bens culturais que faziam referência a colônia, como o Cruzeiro e a Casa de Madeira da CAND.

Em 1987, o Projeto de Lei no 42/87 de autoria do vereador Áureo Garcia Ribeiro, do Partido do Movimento Democrático Brasileiro (PMDB), visava tombar para o patrimônio histórico municipal o Cruzeiro, marco do início do Núcleo Colonial de Dourados (NCD). Na gestão de Luiz Antônio Álvares Gonçalves tornou-se a lei municipal no 1443/1987. O tombamento do Cruzeiro deu-se no Distrito de Vila São Pedro, na antiga cooperativa, marco histórico do início da colonização do NCD. O projeto não teve justificativas, apenas pareceres favoráveis, tanto da Comissão de Justiça, Legislação e Redação, quanto da Comissão de Educação e Cultura. Interessante observar que Vitório José Pederiva, autor do projeto $\mathrm{n}^{\circ}$ 14/84, foi nomeado membro ad hoc do Projeto de Lei no 42/87. Juntamente com o vereador Antônio Noreci da Silva e o presidente da Câmara Archimedes Lemes Soares, defendeu o projeto de lei. O relator, José Alberto Vasconcelos, na Comissão de Educação e Cultura justificou o voto "acrescentando à caneta" que era "plenamente FAVORÁVEL, porque preserva a memória histórica da epopeia de Dourados" ${ }^{15}$. Ao voto favorável deste vereador, acrescentaram-se os de Archimedes Lemes Soares e de Antônio Noreci da Silva. O Cruzeiro representaria, em parte, uma memória histórica associada à CAND, como “epopeia”.

Cabe lembrar que vários trabalhos acadêmicos trataram da CAND. Para Oliveira, no início dos anos 1940, o Governo Federal estava atento às mobilizações das fronteiras

\footnotetext{
${ }^{12}$ Projeto de lei $n^{\circ} 095 / 2005$. Lei municipal $n^{\circ} 2764$ de 16 de agosto de 2005.

${ }^{13}$ Projeto de lei $n^{\circ} 189 / 2009$. Lei municipal n³336, de 4 de janeiro de 2010.

${ }^{14}$ Projeto de lei $n^{\circ} 16 / 2010$. Lei municipal no 3386, de 17 de junho de 2010.

${ }^{15}$ A palavra "favorável" encontra-se em letras maiúsculas no original. Comissão de Educação e Cultura. Votação do parecer do relator. 15 de setembro de 1987, fls 07.
} 
brasileiras ${ }^{16}$. As colônias agrícolas nacionais, como a de Dourados, pautavam-se na fixação do homem no campo através da implantação da pequena propriedade, em torno de 20 a 50 hectares (OLIVEIRA, 1999, p.150). Entre outros aspectos, os lotes eram doados a pessoas "reconhecidamente pobres e aptos a trabalhos agrícolas" (Idem, ibidem). Visava-se a organização de cooperativas destinadas à compra e venda de produtos produzidos ou consumidos pelos agricultores, vinculados ao mercado nacional.

Ainda para Oliveira, "faz-se necessário esclarecer que a CAND foi criada em 28 de outubro de 1943 e instalada em janeiro de 1944, mas sua consecução somente ocorreu em 20 de julho de 1948, quando foi demarcada pelo governo federal” (Idem, p.151). No entanto, segundo a autora, a vinda de colonos seria mais intensa no início dos anos 1950, quando Vargas assumiu a presidência pela segunda vez, entre 1951-1954. De acordo com Silva, "em função da colônia, o município de Dourados transformou-se, ao longo dos anos 1950, de insignificante centro de pecuária tradicional e exploração ervateira, em pólo de produção agrícola do Estado" (SILVA, 2000, p.108). Para o autor, foi a década de 1950 o período áureo da CAND, em que Dourados apresentou um ritmo mais intenso de crescimento demográfico, de cerca de 15 mil habitantes em 1940 para 22.834 em 1950 e 84.955 em 1960 (Idem, p.111). Este crescimento demográfico da cidade esteve acompanhado de vários "serviços elementares". Segundo o autor,

[...] simultaneamente a cidade começou a se equipar com serviços elementares, porém de existência ainda rarefeita na região. Na segunda metade dos anos 1940, foi construído o primeiro hospital. Em 1948, a cidade passou a contar com jornal. Em 1949, foi instalada a primeira unidade de geração de energia elétrica do município (Usina Filinto Muller). Em 1952, foi inaugurada a primeira agência bancária: o Banco Nacional do Comércio e Produção S/A. Nesse período, a cidade foi dotada ainda de emissora de rádio, aeroporto e ensino ginasial (Idem, p.116).

Ainda para Silva, "o processo de dinamização desencadeado pela CAND não favoreceu apenas Dourados, mas foi também um fator decisivo para a ampliação e conformação da atual rede urbana regional, ao dar origem, durante a década de 1950, a diversos povoados e vilas que posteriormente foram transformados em cidades" (Idem,

\footnotetext{
${ }^{16}$ De acordo com Oliveira (1999, p.147), no sul de Mato Grosso, em especial, com a criação do Território Federal de Ponta Porã (1943-1946), com a construção do ramal de Ponta Porã, em 1951, da Estrada de Ferro NOB (em Itahum, em 1948), e com a consolidação da política de colonização (como parte integrante da Marcha para o Oeste), através do encaminhamento de contingentes de trabalhadores, a serem assentados sob a proteção do Estado através da criação da CAND, situada na porção sul do Território Federal de Ponta Porã.
} 
p.111). Destaque para Fátima do Sul, Glória de Dourados, Deodápolis, Douradina, Jateí e Vicentina.

Dois anos depois do tombamento do Cruzeiro, o Projeto de Lei $\mathrm{n}^{\circ}$ 050/89 foi vinculado a CAND através da Casa de Madeira, promovendo uma das principais discussões acerca dos tombamentos via decretos, projetos de leis municipais, no interior do Legislativo douradense. A discussão baseou-se na necessidade de uma lei específica para regulamentar os tombamentos realizados pelos vereadores. Proposto pelo vereador Eduardo Laier, do Partido da Frente Liberal (PFL), o projeto visava uma casa em específico, um dos últimos exemplares construídos no período da CAND. Na justificativa, o vereador frisou diferentes aspectos, dentre os quais se destacaram: 1. "a transmissão do acervo cultural de um grupo, coletividade ou nação só é transferido aos outros quando conservado"; 2. "a preservação expressa grande parte do progresso material e espiritual do homem"; 3. "é vislumbrando a perda desse importante patrimônio que representa o alvorecer da história econômica de Dourados, o que nos motivou a trazer para a apreciação dos nobres pares, o projeto visando o tombamento para o patrimônio histórico do município, o imóvel enunciado", neste caso, "uma casa, construída ainda no governo de Getúlio Vargas, na CAND, sendo uma das últimas residências que marcam o povoamento desta região"; 4. Laier ainda frisou que esperava o apoio do "senhor prefeito municipal" para que "a ideia cresça, viceje e se transforme em realidade"; 5. através da FUNCED e da Secretaria de Educação, "poderemos ter um museu agrícola e o mais importante, o enriquecimento da História do Município" ${ }^{17}$. Vale mencionar que o Museu da CAND foi construído décadas depois, próximo ao Cruzeiro da CAND.

Da extensa justificativa dada pelo vereador deve-se destacar a perspectiva de perda associada à necessidade de preservação, o papel da CAND e sua importância. Ao analisar a "retórica da perda" em discursos que trataram do patrimônio cultural no Brasil, Gonçalves esclareceu que:

[...] o efeito dessa visão é desenhar um enquadramento mítico para o processo histórico, que é equacionado, de modo absoluto, à destruição e homogeinização do passado e das culturas. Na medida em que esse processo é tomado como um dado, e que o presente é narrado como uma situação de perda progressiva, estruturam-se e legitimam-se aquelas práticas de colecionamento, restauração e preservação de 'patrimônios culturais' representativos de categorias e grupos sociais diversos. No entanto, este discurso, que se opõe vigorosamente àquele processo de destruição, é o

17 "Justificativa". Projeto de lei no 050/89. Plenário da Câmara Municipal de Dourados, em 13 de setembro de 1989, fls.03. 
mesmo que, paradoxalmente, o produz. Os objetos que vêm a integrar coleções ou os patrimônios culturais, retirados do contexto histórico, social, cultural e ecológico em que existem originalmente são recodificados com o propósito de servirem como sinais diacríticos das categorias e grupos sociais que venham a representar (2002, p.23).

Para ele, nos discursos de perda, a história, assim como a antropologia e o folclore, desempenhou papel importante na articulação de narrativas sobre o patrimônio cultural no Brasil. O patrimônio cultural é visto, ao mesmo tempo, como perda e apropriação, como ausência e presença. No caso singular da Casa de Madeira da CAND, a autenticidade nela buscada foi o efeito de sua própria perda, em nome da perda que se propôs assegurar sua preservação. Em outros projetos de lei e, nas ações civis públicas analisadas no Capítulo 3, este discurso é novamente observado.

A justificativa do referido projeto de lei ainda estava assinada pelo vereador Eduardo Laier e rubricada por seu colega Frederico Bernardo Holtermann, relator do projeto de lei. Na votação ao parecer do relator na Comissão de Justiça, Legislação e Redação, Holtermann também era membro. O parecer da comissão foi favorável, em 19 de setembro de 1989, com dois votos, de Holtermann e de Francisco Moraes Chico Costa, presidente da comissão.

O projeto de lei apresentou outros pareceres, como o da vereadora Lori Alice Gressler, que o considerou

[...] de grande relevância pelo seu valor histórico cultural, a preocupação do Vereador autor do projeto e merecedor de todos os elogios, pois representa um estímulo para a efetivação de estudos, visando regulamentar de modo geral os tombamentos. Todavia, no meu entender a aprovação é prematura, pois existe uma série de implicações que a lei isolada não abrange. ${ }^{18}$

A perspectiva de Gressler era clara: "regulamentar de modo geral os tombamentos" no interior do município, que uma lei isolada não daria conta. No projeto foram inseridos trechos de livros de "direito público administrativo" que tratava do "tombamento", “indenização" e da "intervenção na propriedade". Além disso, fragmentos da CF88, em especial do artigo 30, no tocante as competências do Município e, sobretudo do item IX "promover a proteção do patrimônio histórico cultural local observado a legislação e a ação

\footnotetext{
18 "Justificativa de voto ao parecer do relator". Ref. Projeto de lei nº50/89. Vereadora Lori Alice Gressler. Membro da Comissão de Educação e Cultura. Dourados, 7 de novembro de 1989. Projeto de lei nº50/89, fls. 18.
} 
fiscalizadora federal e estadual" 19 . Tais inserções, muito provavelmente foram utilizadas para dar suporte à defesa da aprovação do projeto de lei.

A posição contrária da vereadora Lori Alice Gressler se cristalizou naquele projeto de lei pelo Requerimento ${ }^{\circ}$ 497/89, aprovado em 04 de outubro de 1989, em que pediu “vistas" ao Projeto de Lei n ${ }^{0}$ 050/89. Em seguida, a Comissão de Finanças e Orçamento composta pelos vereadores Áureo Garcia e Lori Alice Gressler e, como membro, Gonçalo Padilha e Amorim, rejeitou por maioria de votos, em 1 de novembro de 1989, com parecer contrário ao projeto de lei. Não apenas nesta comissão, mas na de Educação e Cultura, o voto ao projeto de lei permaneceu contrário.

No parecer da Comissão de Finanças e Orçamento se considerou a "relevante importância para a preservação da História e da Cultura, mesmo porque vai buscar na antiga Colônia Agrícola Nacional de Dourados, um material que espelha o início de uma colonização fadada ao sucesso, o que comprova com o progresso que vivenciamos" ${ }^{20}$. Em meio à afirmativa de que a colonização da CAND estaria "fadada ao sucesso" mesclaram-se posições sobre um suposto "fracasso" da CAND (OLIVEIRA, 1999, p.175), observado na migração e/ou na venda dos lotes concedidos ou doados pelo governo a inúmeros colonos. Oliveira ressaltou que em “[...] Fátima do Sul, Vicentina, Jateí e Glória de Dourados existe uma quantidade significativa de moradores remanescentes da CAND, originários do nordeste brasileiro" (Idem, p.217), sendo que "a malha fundiária permanece ainda a mesma estabelecida na época da criação da CAND”, mas em sua maioria pertencem a proprietários que nada têm a ver com o projeto colonizador desencadeado na década de 1940 (Idem, p.180).

O mesmo parecer esclareceu que o "projeto aborda no seu todo, um aspecto unilateral, o que a Comissão não concorda [...] isto porque, não mostrou a ele o respaldo legal". E mais, "somos tecnicamente favoráveis, mas ressaltando que é inoportuno, porque não dispomos ainda a nível municipal de um instrumental jurídico para sua efetivação"21.

A base legal que se referia o parecer da Comissão de Finanças e Orçamento pode ter influenciado a redação e reescrita do projeto de lei que propunha a criação de um Conselho Municipal específico para o patrimônio local. Como professora universitária ${ }^{22}$, Lori Alice

\footnotetext{
${ }^{19}$ Projeto de lei n ${ }^{\circ} 50 / 89$, fls. 08.

20 "Parecer da Comissão de Finanças e Orçamento ao projeto de lei n050/89". Projeto de lei no050/89, fls.15.

21 "Parecer da Comissão de Finanças e Orçamento ao projeto de lei nº50/89". Projeto de lei no050/89, fls.15.

${ }^{22}$ Lori Alice Gressler mudou-se do Rio Grande do Sul para Dourados, em 1971, e, trabalhou nos cursos de licenciatura do Centro Pedagógico de Dourados, na Universidade Estadual de Mato Grosso, depois da divisão do Mato Grosso e criação de Mato Grosso do Sul na Universidade Federal de Mato Grosso do Sul (UFMS) até se aposentar no início dos anos 1990. Formada em Pedagogia pela Universidade Federal de Santa Maria (UFSM)
} 
Gressler fez viagens a São Paulo para observar experiências acerca do patrimônio e dos conselhos municipais. A preocupação da vereadora ao dar parecer contrário, ao que parece, estava vinculada ao interesse de criar um meio participativo/democrático através do Legislativo, da atuação do poder público e da comunidade, que pudesse agregar a complexidade do tombamento e da preservação. Entre as várias discussões na Câmara Municipal, Gressler defendeu e promoveu debates junto à comunidade para constituir a LOM.

O parecer contrário expedido pela comissão, rejeitado pela maioria em plenário, acrescentou ser:

[...] necessário esse instrumental visto que gera o Tombamento uma série de implicações que vão envolver o Poder Público Municipal, os proprietários do imóvel, os seus herdeiros e fatores que devem e precisam ser amplamente analisados. Por outro lado, a Comissão entende que o Município deva criar um Parque Histórico onde abrigará os materiais tombados, devidamente reconstruídos, obedecendo todas as suas características originais. Daí porque propõe seja [sic] o Projeto retirado pelo nobre Vereador, autor da propositura, para uma representação em tempo oportuno, quando já dispusemos dos mecanismos legais para a sua efetivação. ${ }^{23}$

A aprovação do Projeto de Lei $n^{\circ}$ 050/89, da Casa de Madeira da CAND, foi responsável por um debate sobre a necessidade de cautela nos tombamentos realizados pela Câmara Municipal, pois envolveu, neste caso em específico, a desapropriação de imóvel privado, ressaltando-o como um dos aspectos no Projeto de Lei ${ }^{\circ}$ 021/90 e mantido na Lei Complementar $n^{\circ} 02 / 90$.

No Projeto de Lei $n^{\circ}$ 050/89, algo interessante chamou atenção nos pareceres expedidos pelas comissões, tanto a de Orçamento e Finanças quanto a de Educação e Cultura. A proposta apresentada pelos vereadores reforça a argumentação dos dois pareceres ao esclarecer a falta de base legal nas leis do município, sobretudo, num momento de recente aprovação da CF88, que sinalizava maior autonomia aos municípios brasileiros. Estes, por sua vez, deveriam seguir a Constituição Federal, a Estadual e elaborar suas LOM's. É válido considerar não só o voto contrário, mas as sugestões dadas ao projeto de lei, como a criação de um "parque histórico".

obteve sua pós-graduação nos Estados Unidos, mestre em Educação pela Organização dos Estados Americanos (OEA/UFSM), em 1971. Doutora em Educação pela Mississippi State University, em 1976, e pós-doutora pela mesma Universidade, em 1984, Cf. 〈http://buscatextual.cnpq.br/buscatextual/visualizacv.do?id=K4773782P2 >. Segundo Vasconcelos (2014, p.194) "Lori Alice Gressler provavelmente foi a primeira professora com Doutorado em Educação no Estado de Mato Grosso, antes da divisão".

23 "Parecer da Comissão de Finanças e Orçamento ao projeto de lei nº50/89". Projeto de lei n050/89, fls. 15. 
Cabe frisar que no parecer citado anteriormente, Gressler, que também era integrante da Comissão de Educação e Cultura, em 7 de novembro de 1989, observou a "aprovação prematura" do projeto, reiterando aspectos vistos no parecer anterior na Comissão de Finanças e Orçamento. O parecer da vereadora foi contrário ao parecer do relator da Comissão de Educação e Cultura, Carlos Roberto Cristino de Oliveira. Mesmo assim, o relator referiu-se a artigos da Constituição Federal e Estadual que tratam das atribuições do Município em “promover a proteção do Patrimônio Histórico e Cultural”, defendendo que:

[...] como a casa de madeira referida no bojo do Projeto marca um período histórico da nossa região, ou seja, marca o início da colonização desta extensa área, através da criação da Colônia Agrícola Nacional de Dourados, pelo então Presidente da República Getúlio Vargas em 1943, entendo que deve ser preservada. E, a única forma de preservá-la é o tombamento para o Patrimônio Histórico de Dourados, pois desta forma o Município promoverá meios de protegê-la contra a ação corrosiva do tempo ou mesmo contra a destruição pelos próprios proprietários. Portanto, sou favorável a tramitação do Projeto. ${ }^{24}$

A importância dada pelo vereador e também professor à Casa de Madeira tinha forte relação com a CAND e pelo que representava para Dourados. Ele ainda alertou para a "destruição" ou "ação corrosiva do tempo", numa defesa pelo tombamento associada à preservação.

Em 1990, em paralelo às discussões da LOM e elaboração do Conselho Municipal específico ao patrimônio, elegeu-se por projeto e lei municipal outro patrimônio vinculado à CAND, denominado Marco de Cimento, que "servia como divisa do perímetro suburbano e a Colônia Agrícola Nacional de Dourados". O Projeto de Lei nº 007/90, de autoria do vereador Archimedes Lemes Soares (PMDB) e presidente da Câmara, tornou-se a Lei Municipal $n^{\circ}$ 1621, de 07 de junho de 1990. Assim como na tramitação do Projeto de Lei no 050/89, ocorreu em 17 de abril de 1990 pedido de vistas pelo vereador Ivo Cratiu da Silva (PMDB), rejeitado em 18 de abril de 1990. No parecer da Comissão de Educação e Cultura, composta pelo próprio Ivo Cratiu da Silva, Bela Barros e Lori Alice Gressler, em 24 de abril de 1990, o parecer foi favorável contendo a solicitação de um "memorial descritivo". Defendeu-se que a patrimonialização do Marco de Cimento deveria ter "[...] respaldo de pessoas que militam na área da cultura" e deveria permanecer "em seu local de origem, demarcado, acompanhado de

\footnotetext{
24 “Comissão de Educação e Cultura”. Parecer do relator. Ref. Projeto de lei nº50/89. Carlos R. C. de Oliveira. Dourados, 7 de novembro de 1989, fls. 17.
} 
placa com descrições”. A emenda aditiva de autoria do vereador Alberto Alves dos Santos, do Partido Trabalhista Brasileiro (PTB), propôs a denominação do Marco de Cimento de Getúlio Vargas e, em 25 de abril de 1990, teve parecer favorável da Comissão de Justiça, Legislação e Redação, assinado por Frederico Bernardo Holtermann e o proponente Archimedes Lemes Soares, frisando que "nada mais justo esta homenagem a Vargas".

De modo geral, os pareceres das comissões foram sucintos. Raras foram as emendas aditivas. Os votos, em sua maioria, favoráveis aos projetos de lei. Poucos justificaram, além de votar pelo "sim" ou "não". No entanto ocorreram pareceres contrários. Observou-se certa variedade e contradição na postura de determinados vereadores, dependendo das circunstâncias, das relações de proximidade estabelecidas entre os próprios vereadores e entre os partidos ou até entre os que propunham e, ao mesmo tempo, compunham as comissões que aprovariam ou não os projetos de lei apresentados. Por exemplo, o voto contrário da comissão que Gressler integrava foi vencido por dois votos favoráveis, um do próprio Carlos Roberto Cristino de Oliveira e outro de Francisco Mendes Chico Costa, membro ad hoc do Projeto de Lei $\mathrm{n}^{\circ}$ 050/89, nomeado por Carlos Roberto Cristino de Oliveira. Os projetos da Casa de Madeira da CAND e do Marco de Cimento foram aprovados e desencadeou a elaboração de lei municipal específica ao patrimônio local, que resultou na formação do Conselho Municipal de Preservação do Patrimônio Histórico, Cultural e Ambiental de Dourados.

\section{Referências}

AZEVEDO, Paulo Ormindo de. "Renato Soeiro e a institucionalização do setor cultural no Brasil” In: AZEVEDO, Paulo O. D. de; CORREAA, Elyanne L. (orgs.). Estado e sociedade na preservação do patrimônio. Salvador: EDUFBA/IAB, 2013, p.19-55. Disponível em <https://repositorio.ufba.br/ri/bitstream/ri/16772/1/estado-sociedade-na-preservacaopatrimonio.pdf > acesso em 10 de setembro de 2017.

AZEVEDO, Paulo Ormindo de. "PCH: a preservação do patrimônio cultural e natural como política regional e urbana”. In: Anais do Museu Paulista. São Paulo, v.24, n.1, p.237-256, jan.-abr.2016. Disponível em: <http://www.scielo.br/pdf/anaismp/v24n1/1982-0267-anaismp24-01-00237.pdf> acesso em 20 de fevereiro de 2018.

CAMPOS, Yussef Daibert Salomão de. Percepção do intangível: entre genealogias e apropriações do patrimônio cultural imaterial. Goiânia: Arraes, 2017.

CHARTIER, Roger. A história ou a leitura do tempo. $2^{\mathrm{a} e d .}$ Belo Horizonte: Autêntica, 2010.

CHAUÍ, Marilena. Cidadania Cultural: o direito à cultura. 1ªreimp. São Paulo: Fundação Perseu Abramo, 2006. 
CHUVA, Márcia. "Por uma história da noção de patrimônio cultural no Brasil". In: CHUVA, Márcia (org.). Revista do Patrimônio Histórico e Artístico Nacional. Dossiê História e Patrimônio. IPHAN/Minc: Brasília-DF, n³4, 2012, p.147-167.

CHUVA, Márcia. "Possíveis narrativas sobre duas décadas de patrimônio: de 1982 a 2002”. In: SCHLEE, Andrey R. (org.) Revista do Patrimônio Histórico e Artístico Nacional. Iphan: 1937-2017, n³5, 2017, p. 79-104.

CONCIANI, Aline; SANTOS, Danielle C. dos. "Surgimento da federação brasileira e sua concretização na atual constituição federal". Revista de Direito Público, Londrina, v, 4, n. 3, p. 268-281, $\quad$ set./dez. 2009.2 Disponível <http://www.uel.br/revistas/uel/index.php/direitopub/article/viewFile/10881/9517> acesso em 14 de fevereiro de 2018.

CONVENÇÃO para a salvaguarda do patrimônio cultural imaterial, aprovada em 2003. Disponível em <https://ich.unesco.org/doc/src/00009-PT-Portugal-PDF.pdf >acessado em 28 maio 2018.

FEBVRE, Lucien. “Aula II - Definições teóricas ou história das palavras”. Honra e pátria. Rio de Janeiro: Civilização brasileira, 1998, p.52-59.

GONÇALVES, José R. S. A retórica da perda: os discursos do patrimônio cultural no Brasil. Rio de Janeiro: UFRJ/IPHAN, 2002.

HUNT, Lynn. A Nova História Cultural. São Paulo: Martins Fontes, 1992.

HARTOG, François. Regimes de historicidade: presentismo e experiências do tempo. Belo Horizonte: Autêntica, 2014.

HARTOG, François. "Tempo e patrimônio". Varia História. Belo Horizonte, vol.22, n³6, jul-dez 2006, p.261-273.

HARTOG, François. "Tempo, história e a escrita da história". Revista de História. 148 (1 2003), p.09-34.

INSTITUIU o registro de bens culturais de natureza imaterial que constituem patrimônio cultural brasileiro, cria o programa nacional do patrimônio imaterial e dá outras providências. Disponível <http://www.unesco.org/culture/natlaws/media/pdf/bresil/brazil_decreto_3551_04_08_2000_ por_orof.pdf> acesso em 28 maio 2018.

KOSELLECK, Reinhart. Futuro passado: contribuição à semântica dos tempos históricos. Rio de Janeiro: Contraponto, 2006.

LINO, Fernanda N. da Costa. A preservação do patrimônio cultural urbano: fundamentos, agentes e práticas urbanísticas. 2010, 196f. Tese (doutorado em Direito), USP. São Paulo.

MACHADO, Jurema. "A UNESCO e o Brasil: trajetória de convergências na proteção do patrimônio cultural”. In: FUNARI, P. P. A. (Org.); PELEGRINI, S. (Org.); RAMBELLI, G. 
(Org.). Patrimônio cultural e ambiental: questões legais e conceituais. São Paulo: Annablume, v. 1. p. 116- 128, 2009.

MACMILLAN, Margaret. Usos e abusos da história. Rio de Janeiro: Record, 2010.

MENESES, U. T. B. de. "O campo do patrimônio cultural: uma revisão de premissas". In: SUTTI, W. (Coord.). I Fórum Nacional do Patrimônio Cultural: sistema nacional de patrimônio cultural - desafios, estratégias e experiências para uma nova gestão. Brasília: IPHAN, 2012.p. 25-39. Disponível em $<$ http://portal.iphan.gov.br/uploads/ckfinder/arquivos/MENESES_Ulpiano_O-campo-dopatrimonio-cultural---uma-revisao-de-premissas.pdf > acesso em 12 jan. 2018.

MENESES, Ulpiano T. B. de. "Repovoar o patrimônio ambiental urbano". In: SCHLEE, Andrey R. (org.) Revista do Patrimônio Histórico e Artístico Nacional. Patrimônio: desafios e perspectivas, n'36, 2017.p. 39-52.

NOGUEIRA, Antônio Gilberto Ramos. O campo do patrimônio cultural e a história: itinerários conceituais e práticas de preservação. Antíteses. v. 7, n. 14, p. 45-67, jul. - dez. 2014.

OLIVEIRA, Benícia C. de. A política de colonização do Estado Novo em Mato Grosso (1937-1945). 1999. 182 fls. Dissertação (Mestrado em História). UNESP. Assis.

PESAVENTO, Sandra J. História \& História Cultural. $3^{\mathrm{a}} \mathrm{ed}$. Belo Horizonte: Autêntica, 2012.

POSSAMAI, Zita. "O lugar do patrimônio na operação historiográfica e o lugar da história no campo do patrimônio”. Anos 90. Porto Alegre, v.25, n.48, p. 23-49, dez. 2018.

QUEM pode efetuar um tombamento? IPHAN Disponível em <http://portal.iphan.gov.br/perguntasFrequentes/detalhes/60> acesso em 10 fev. 2018.

SANT'ANNA, Márcia. “Cidade-atração: Patrimônio e valorização de áreas centrais no Brasil nos anos 90". Cadernos PPG-AU, FAUFBA, Salvador, v. 2, n. 2 [número especial], p. 43-58, 2004. Disponível em <https://portalseer.ufba.br/index.php/ppgau/article/view/1686> acesso em 20 ago. 2018.

SANTIAGO JÚNIOR, Francisco das C. F. "Dos lugares de memória ao patrimônio: emergência e transformação da "problemática dos lugares"”. Projeto História. São Paulo, n.52, pp. 245-279, jan-abr, 2015.

SANTOS, Marina de S. Dourados: planejamento, olhares sobre a cidade (1970-2003). 390 f. 2016. Tese (Doutorado em História). UFGD, Dourados.

SANTOS JÚNIOR, Orlando A. dos; AZEVEDO, Sérgio de; RIBEIRO, Luis C. de Q. (Orgs.) Governança democrática e poder local: a experiência dos conselhos municipais no Brasil. Rio de Janeiro: Revan/Fase, 2004.

SILVA, Mário César Tompes da. Novos rumos da política habitacional e o processo de urbanização de Dourados. 2000. 324fls. Tese (Doutorado em Geografia). USP. São Paulo. 
VASCONCELOS, Luiza Melo. “Lori Gressler”. In: PELLEGRINI, Fábio \& SENNA, Melly F. G (orgs). Vozes da literatura. Campo Grande: FCMS, 2014, p.192-197. 